\title{
دولة تحت التشكيل \\ حوار النفي وإثبات الوجود \\ ( كردستان العراق إنموذجا )
}

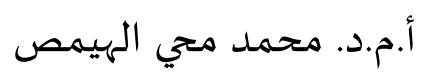

الجامعة المستنصرية -كلية التربية

المقدمة

الأكراد أحدى القوميات التي تتكل نسبة من سكان العراق ، وقد اختلفت الدصادر في تقدير أعدادهم

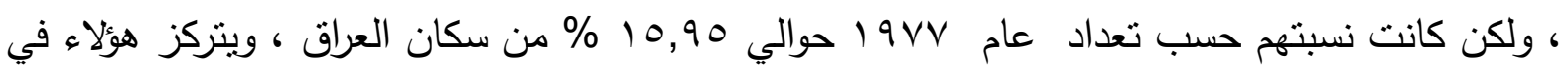

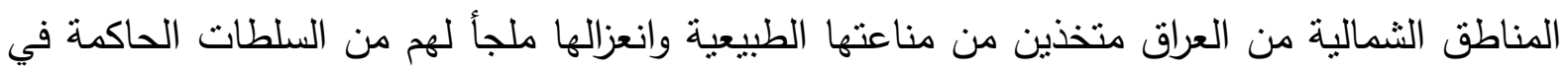

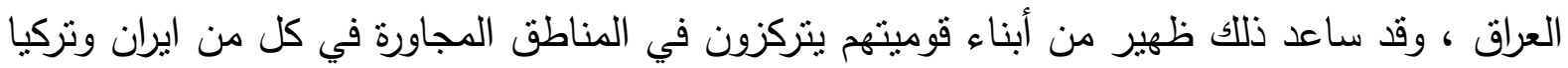

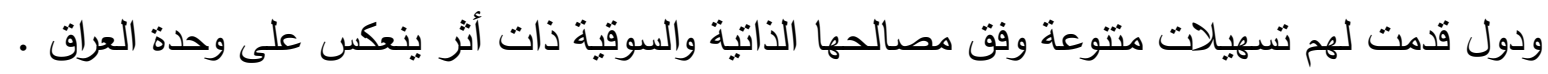
وإذا تصفحنا العلاقات السياسية والعكرية بين الحكومات العراقية والقيادات الكردية فأنها تتبع إبعادا مختلفة بين فترة وأخرى وقد تحدث مواجهات تواكب التغيرات السياسية التي تجتاح المنطقة . لقد سمت الأوضاع الدولية والعراقية خاصة بعد عام .199 وعام r... على تصعيد الحركة

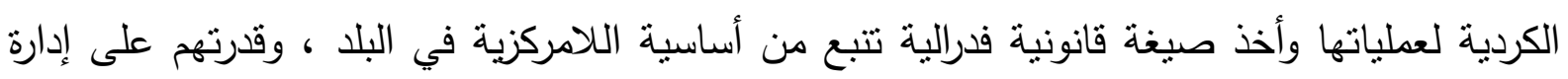

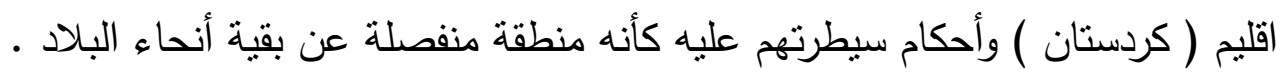

ولأن مهمة هذا البحث هي استتراف مستقبل العراق في عقده المقبل ، كان لابد من أن تقوم هذه

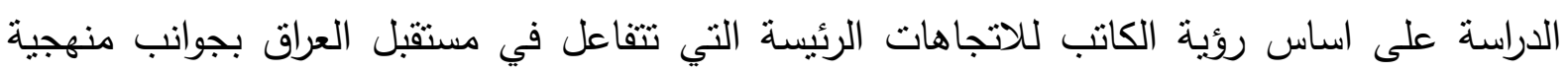

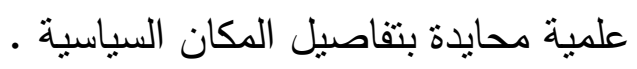


وطالما واصلت المسألة الكردية التحرك على خط بياني صاعد في العراق ( هدف البحث ) أصبحت

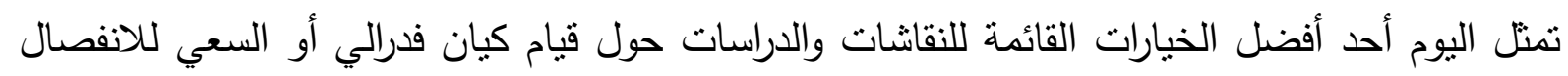

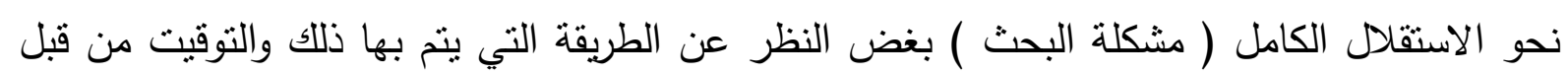

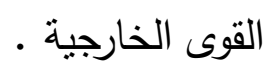

إذن هذان النموذجان موجودان ، لذلك تفترض الدراسة على الرغم مما ذكرناه ، أنهما مصدر قلق في القي

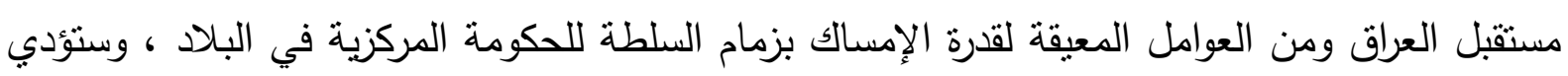

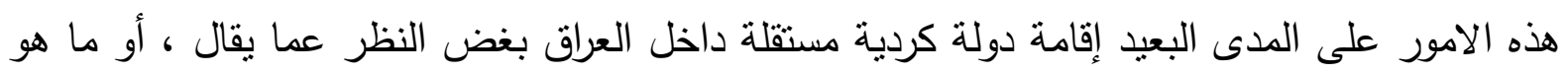

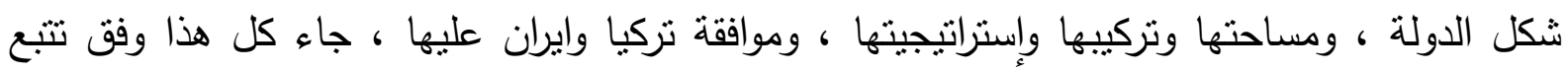
وتحليل جغرافي سياسي علمي وكما يأني : أولا : الدولة ثانيا : كردستان العراق ثالثا : لمحة عن اكراد العراق رابعا : كردستان والفدرالية في العراق خامسا : تكوين دولة كردية في العراق وخاتمة تؤكد التطلعات السياسية للاكراد والسعي لكسب المجتمع الدولي لقيام دولة كردية في العراق أولا : الدولة أ- ما هي الدولة : n - n 
يزعم أحد الدارسين لهذا الموضوع أنه جمع مئة وخمسة واربعين تعريفا لهذا الدفهوم ، وهذا يعني عدم الاتفاق على تعريف موحد كافي وشافي للاولة بين المتعاطين بالسياسية ومسلكياتها ، لكن تميل أكثرية الباحثين الى الآخذ بالدفهوم التالي للاولة :

(( هي أحدى المؤسسات الاجتماعية ، تتميز عنها بأنها تحكم على ضوء قوانين تسنها وتنترها حكومة

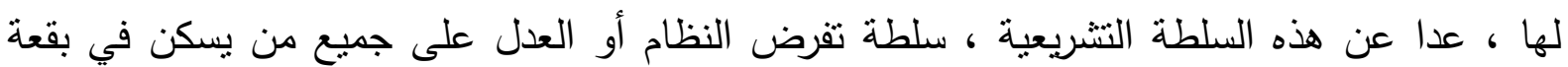

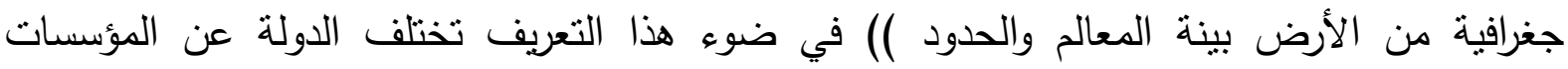

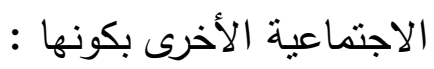

تضم جميع الساكنين في بقعة معينة من الأرض تهتم بالمحافظة على النظام الاجتماعي بواسطة حكومة

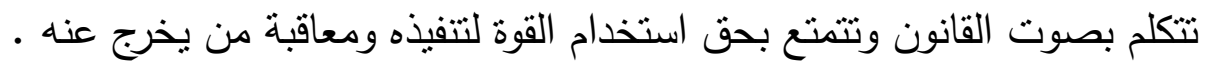

بكلمات أعم (( تتشأ الدولة بنشوء حكومة مستقرة في شعب مستقر على بقعة معينة من الأرض )) .

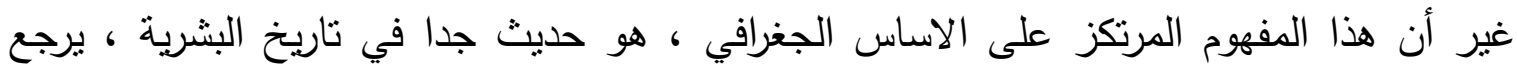

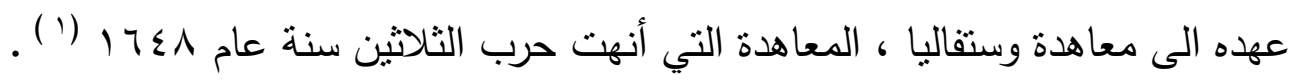
ما يهمنا في هذا السياق أن نضيف ما يقوله الديب (( نظرا لصعوبة وضع تعريف للدولة فمن

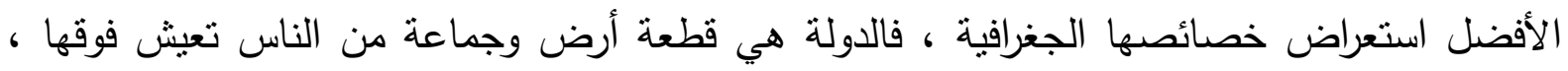

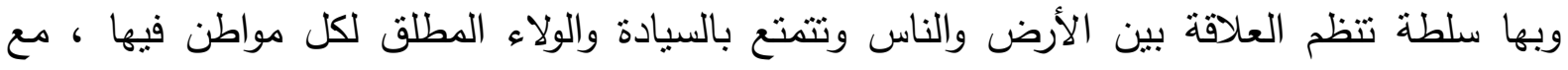

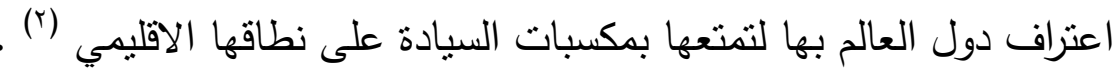
ولن نذهب الى أبعد من ذلك بما يشير الى الدولة ولكن كيف تتشأ الدولة ؟ تتشأ الدولة في أول أمرها

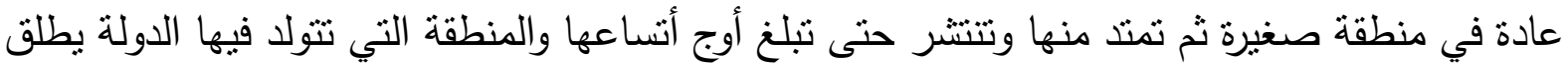

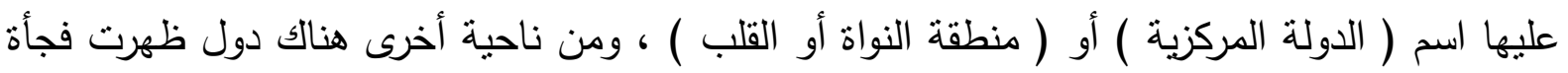


دون أن يكون لها نواة حقيقية ومن أمتلنها جميع الدول التي نشأت نتيجة انقسام أو انشطار دولة

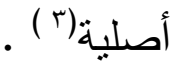

لعل في مقدمة شروط قيام الدولة كلها ، شرطا طبيعيا ، بل بديهيا فالنشأة فيه والدعوة الى حياة

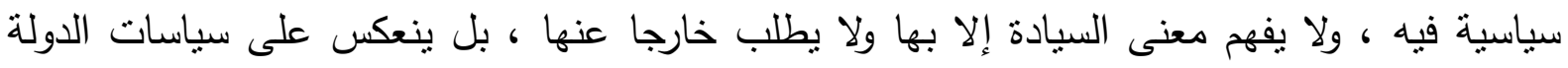

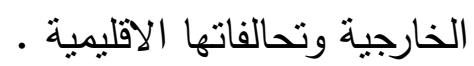

$$
\begin{aligned}
& \text { وهكذا يقودنا الحديث الى سؤال معرفي تاريخي : } \\
& \text { هل للدولة الكردية شواهد في التاريخ ؟ }
\end{aligned}
$$

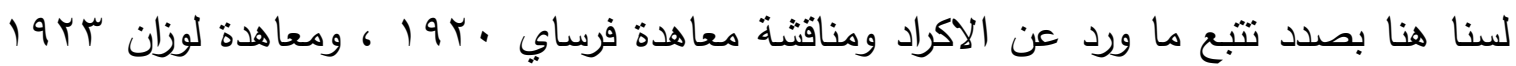

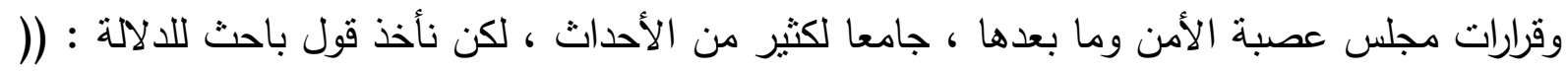

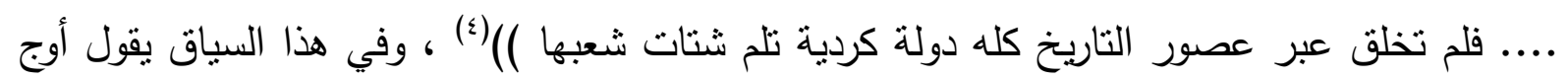
الآن (( ولربما كانت كلمتتا الكرد وكردستان ( التي تعني موطن الكرد ) متميزتين بتذكرهما كأسمين لأقدام

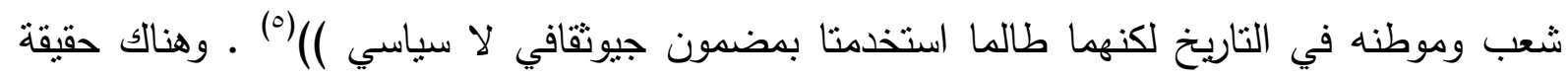

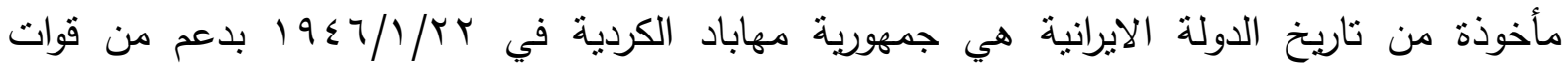

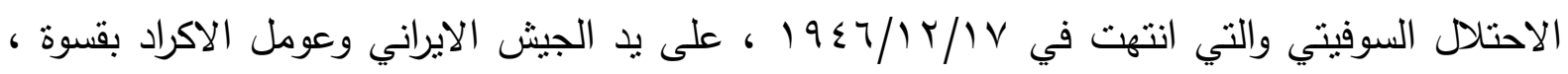

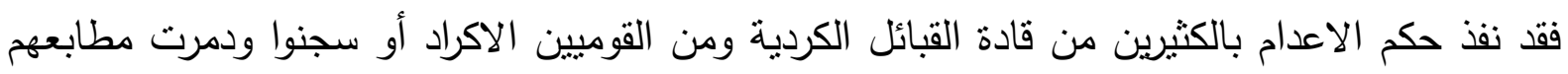

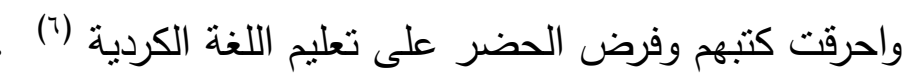

ولاثتك أن الدولة الكردية لا تزال غائبة عن الواقع السياسي الدولي حتى الأن ، رغم وجود نطورات

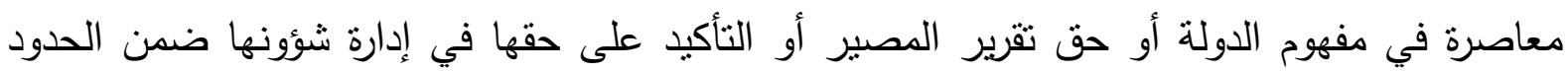


بعد هذا لابد من أن نسأل عن الحيز المكاني أو ما يعرف ( كردستان العراق ) والتي تتنتر فيها

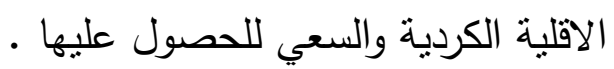
هذا ما سنحاول الإجابة عليه في النقطة الأخرى من البحث . ثانيا : كردستان العراق

لابد أن نتفص مفهوم ( كردتان ) الذي أكتسب أبعادا ودلالات شتى في مسار الأحداث وارتبط

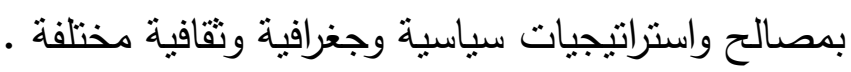

$$
\text { أ- كردستان : معناها وحدودها }
$$

سنعرض على سبيل المثال بعض تعريفات كلمة كردستان كما ذكرتها المصادر العلمية وهي : لعل أقدم المصادر التي ظهر فيها اصطلاح كردستان هي المصادر اليونانية ، فقد سمى الكتاب

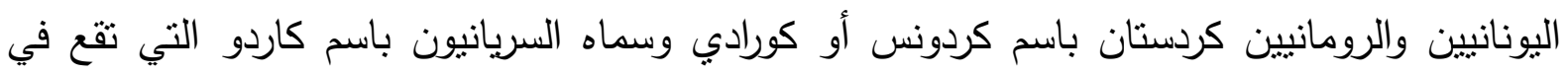

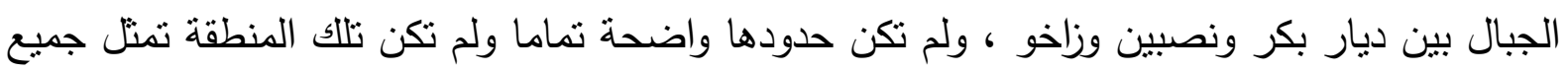

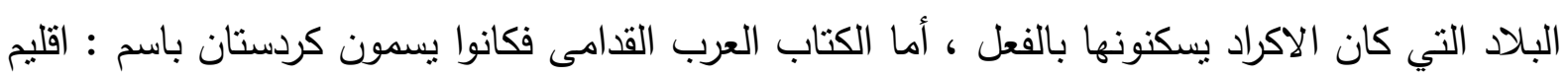

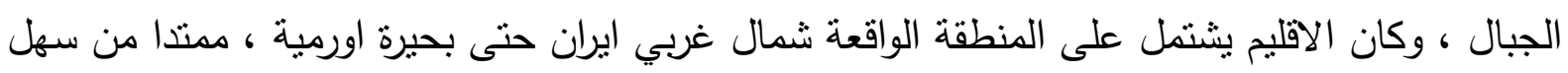

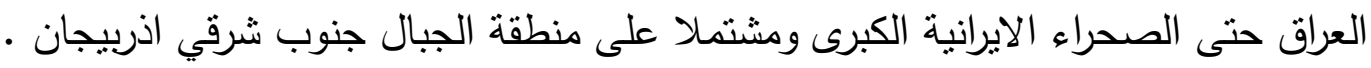

وكلمة كردنان كاصطلاح جغرافي ظهرت لأول مرة في القرن الرابع عشر في عهد السلاجقة ،

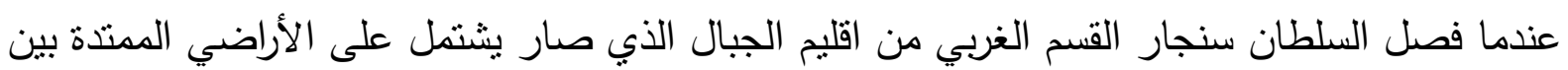

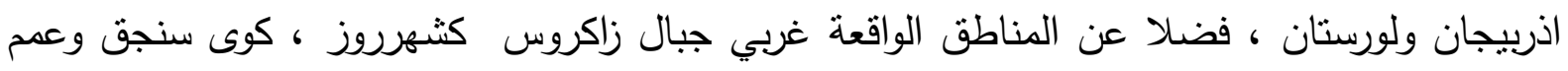

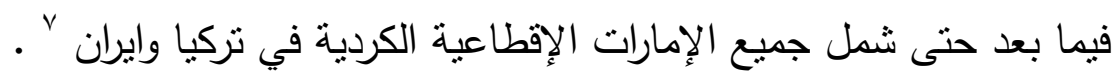


يقول العلامة محمد أمين زكي بك ، أن لفظ كردستان في الأصل أطلقه السلجوقيون .. أما على المنطقة

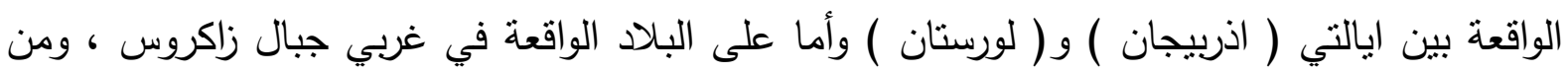

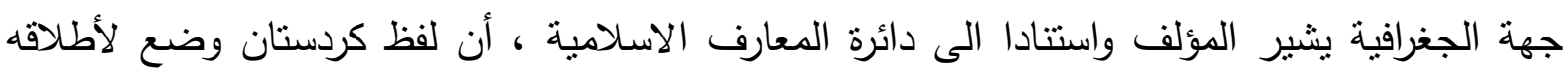

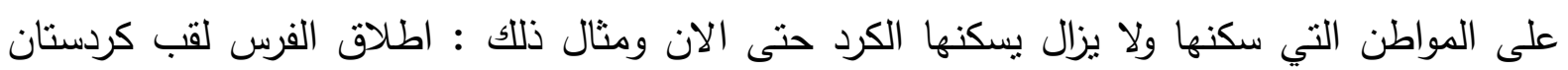

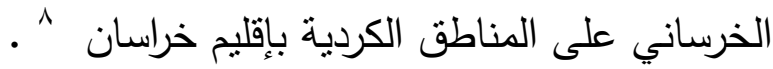

ومن رأي الاستاذ جلال الطالباني يتضح ان ( كردستان تعني بلاد الكرد وتتألف لفضياً من كلمتين

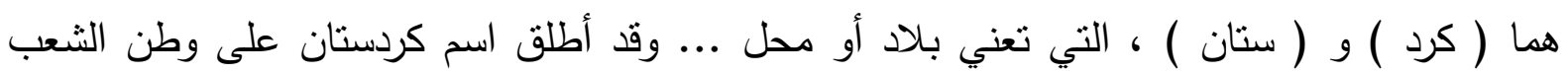

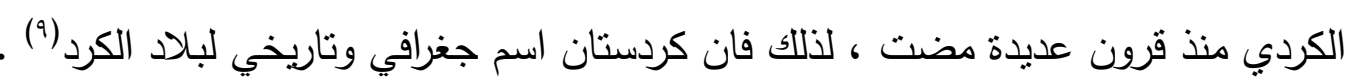

يتضح مما سبق ان تفاصيل هذه المصادر ربطت كردستان بمستقرات الكرد والصفة الغالبة عليها خصائص الاقاليم الجغرافية في مساحة من الارض صغرت الم كبرت ، يرسم صفتها المميزة مدلول

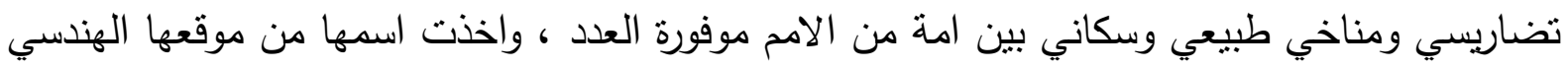

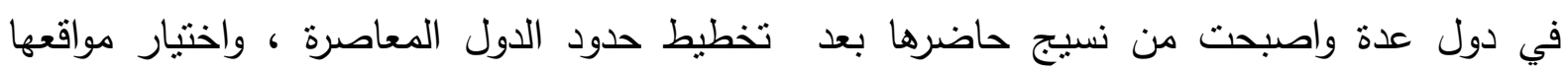

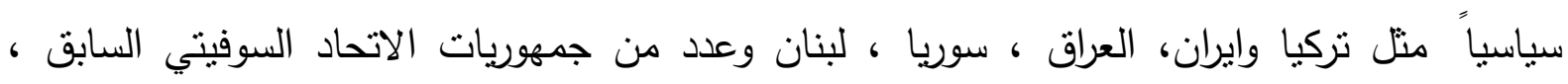

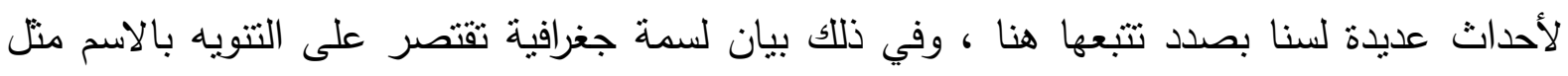
كردستان العراق او تركيا او ايران ولن توضع في تخطيط الدول وتطييقاتها والمعاهدات وتفاصيلها المعلنة

ولا يقتصر الحديث عن ما ذكر عن كردستان ، بل نذهب الى من سكن فيها من الاكراد بإيجاز ، اذ لا يزال الباحثون يختلفون في اصلهم (·) ، مما اوجد اراء عدة حول ذلان ولك والمرجح انهم احفاد الميديين

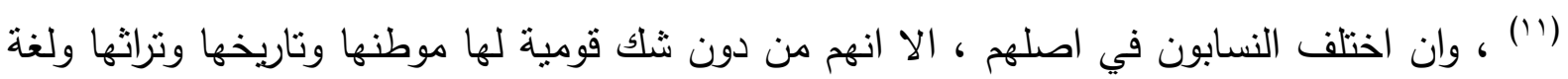

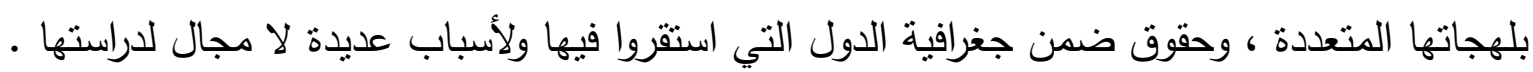


وجدت هذه القومية نفسها تتصارع مع الحكومات في نطاق الحدود السياسية للدول المتواجدة بها من اجل حقوق الاقلية في الدد الادنى او حق تقرير المصير او الانفصال وتكوين وحدة سياسية جديدة في ني

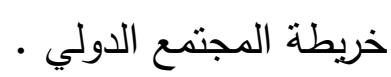
في هذا المجال نركز على العلاقة بين الدولة العراقية والاقلية الكردية ، وهي علاقة متشابكة ومعقدة

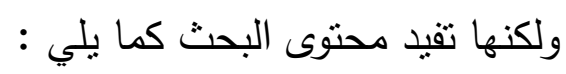
ثالثا : لمحة عامة عن اكراد العرلق عن مستوى الواقع الجغرافي يلاحظ النطبيقات الاحصائية المرتبطة بنظم المعلومات السكانية تعداد 19VV

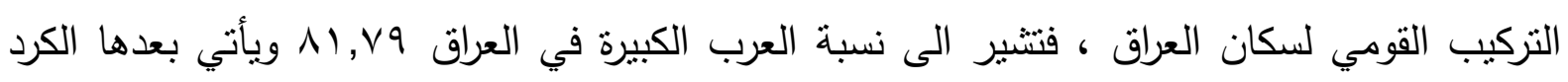

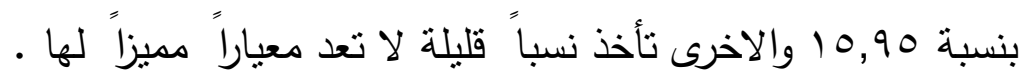

الامر الطبيعي الاخر من العامل الجغرافي يتضمن نوزيع او تركز الاكراد جغرافياً ، اي المناطق

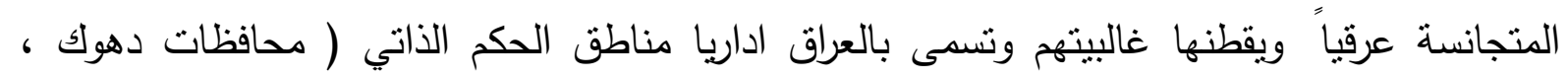

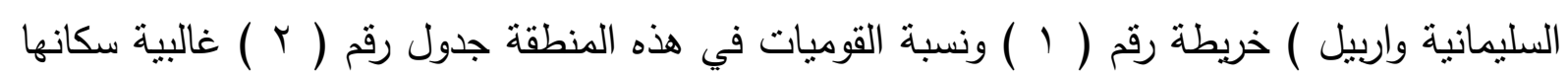

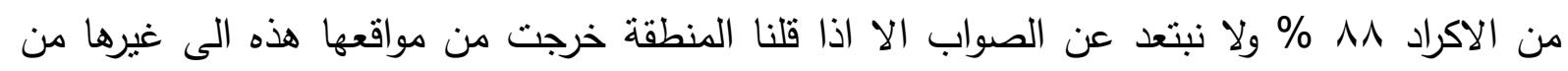

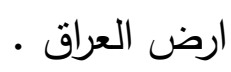

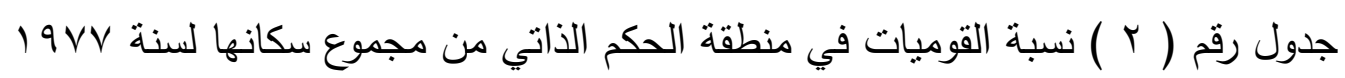

\begin{tabular}{|c|c|c|}
\hline النسبة \% & القومية & ت \\
\hline$\Lambda \wedge$ & |الاكراد & 1 \\
\hline $9, \leqslant 0$ & العرب & $r$ \\
\hline
\end{tabular}




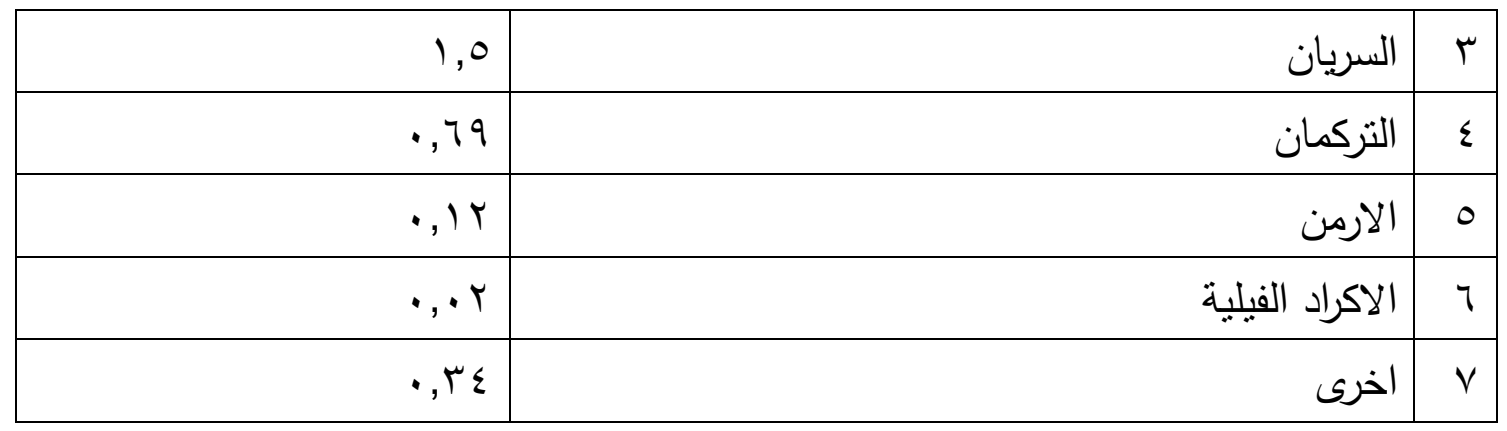

المصدر : العداد السكاني في العراق لسنة lavV

وما يهمنا هنا عموماً التطور التاريخي السياسي للحركة الكردية في العراق او الصراع بين الحكومات العراقية والقيادات الكردية في اطار سياسي واحد لدولة مستقلة ( العراق )

ونستطيع ان نواكب تطورات الحركة الكردية في العراق بشكل منتظم بل طرح اهم ما تتميز به ويخدم

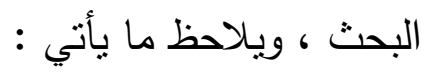

أحتاج الاكراد عقود تقريبا من النضال المسلح ليحققوا مستوى الحكم الذاتي بيان الحادي عشر من

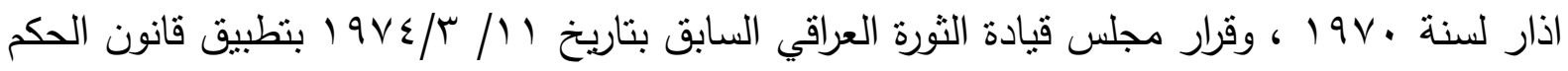

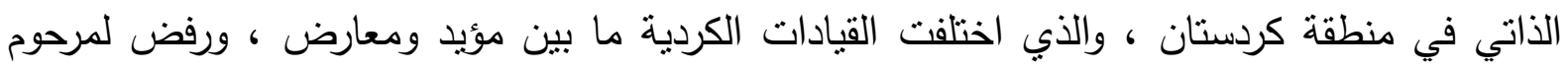

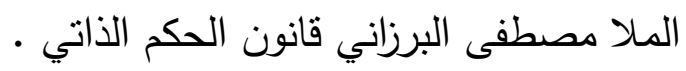

ومن الانصاف القول بأن القانون اكبر بكثثر مما حققه الاكراد في الدول الاخرى ، لكنه يفتقر من

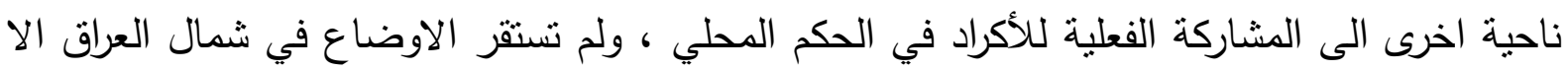
باتفاقية الجزائر عام 19v0 التي جعلت ايران تسحب دعمها للأكراد مقابل تخلي العراق عن مطالبته

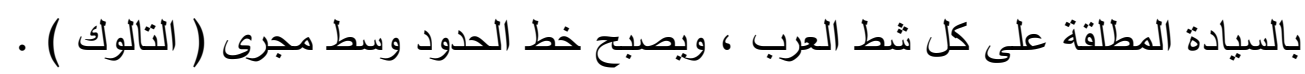
وتتشير تطورات القضية الكردية الى / / / 199 وما صاحبها بعد ذلك اعلان الولايات المتحدة

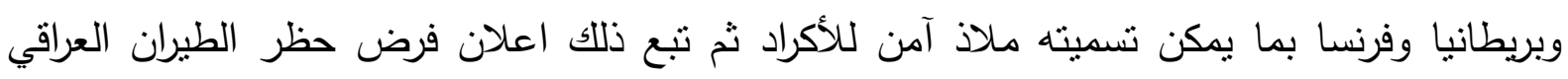


شمال دائرة العرض حبْ لأغراض سياسية بالنسبة لهذه الدول ولأول مرة في تاريخ الاكراد نوفير غطاء

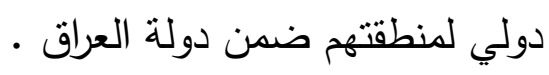

وما يمكن ان نتابع ، مثل ما حصل في عام ع99 199 في شمال العراق ووقع الحرب الاهلية بين

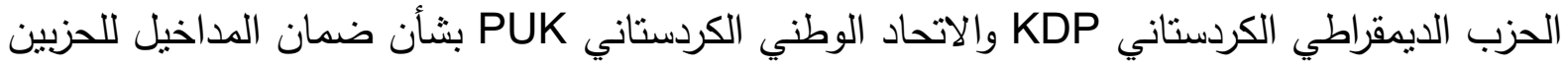
وقيادة الحركة القومية الكردية ، وما حدث في آب 1997 عندما استتجد الحزب الديمقراطي الكردستاني

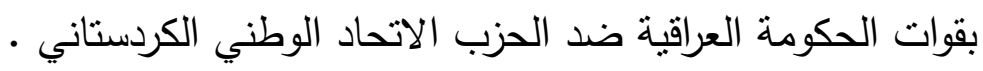

ولسنا بصدد تتبع الاحداث وفق تعاقب زمني محدد ، لكن نثير الى نقلة نوعية في تاريخ القضية

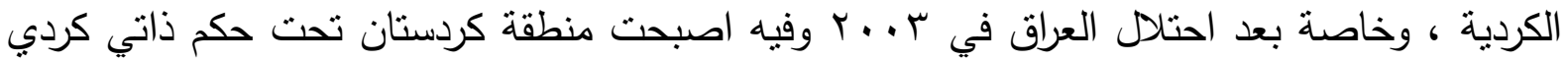

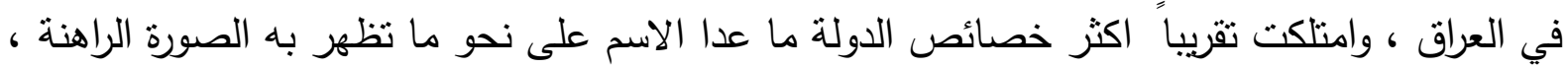
والحديث يدور عن عراق موحد من خلال دولة مدنية ديمقراطية فرالية ، ويدخل تحت هذا العنوان فدرالية

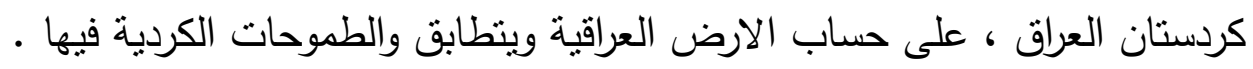

ان مناقثة هذا الامر يقوم على اساسين : بقاء الاكراد في الدولة العراقية ضمن منطقة حكم ذاتي والثناني مؤشر على التقسيم المدبر للاولة العراقية ، من النتائج البارزة للسيطرة الامريكية على العراق السؤال الذي يطرح نفسه الان ، هو : ما حقيقة الأمر ؟

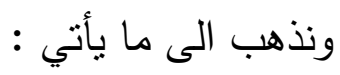
رابعاً : كردستان وإلفدرالية في العرلق حست المادة الرابعة من قانون ادارة الدولة العراقية المسألة المتعلقة بشكل الدولة العراقية التي ستظهر بعد تاريخ التاسع من نيسان عام ب...T ، اذ نصت على ان : (( نظام الحكم في العراق جمهوري اتحادي فدرالي ، ديمقراطي ، تعددي ، ويجري تقاسم السلطات بين الحكومة الاتحادية والحكومات الاقليمية والدحافظات والبلديات والادارات المحلية ويقوم النظام الاتحادي على اساس الحقائق 
الجغرافية والتاريخية والفصل بين السلطات وليس على اساس الاصل او العراق او الاثثية او القومية او

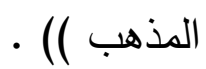

وهنا لن نتعرض للفدرالية على المستوى النظري ، والتعريف بالدولة الفدرالية او الاتحادية ، وهل

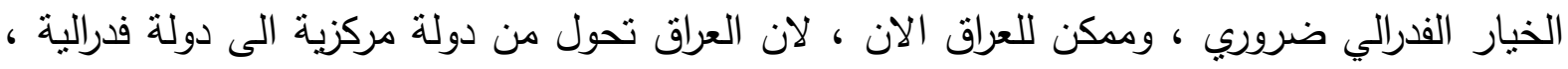
وفقاً للقانون الدستوري الفي ضروي ،

من شأن ذلك ان يبقى الاكراد العراقيون على درجة عالية من الحكم الذاتي الغير منقوص كأدنى

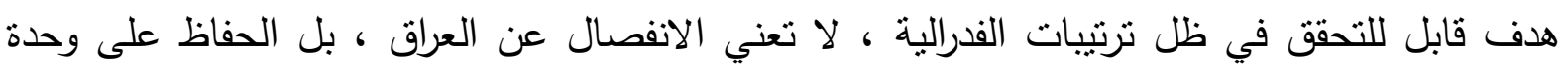

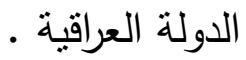
ومع ان هذا ا لاستتناج مثير للجدل ، لكنه يحتل الحيز الاكبر في مقابلات المسؤولين الاكراد والعرب

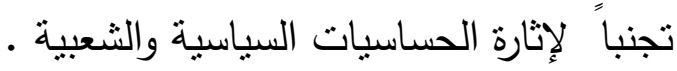

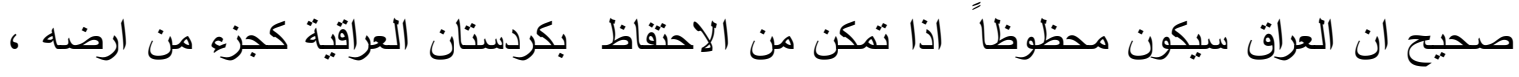

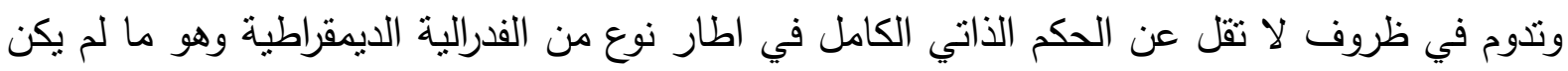

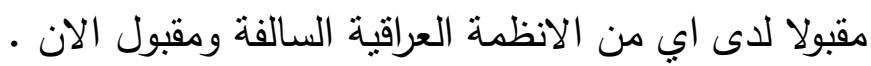

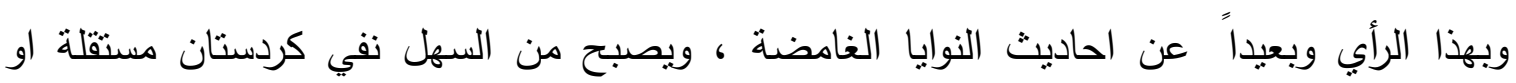

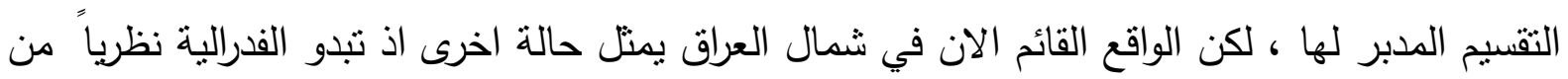

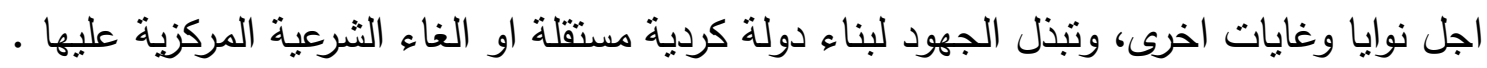
ولو كان ذلك معروفاً من خصائص المكان ، فمن المفروض ان يعالج بجوانب علمية ومنهجية وكما يلي : 
خامساً : تكوين دولة كردية في العرق :

لقد هيمن على تاريخ الاكراد العراقيين نضال ام تمرد ضد القوة المسيطرة في الدولة العراقية العربية ،

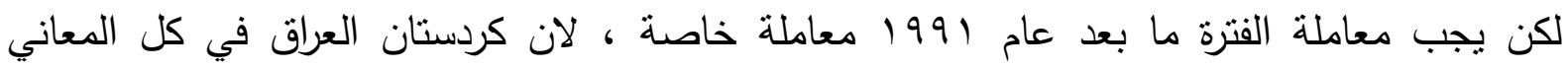

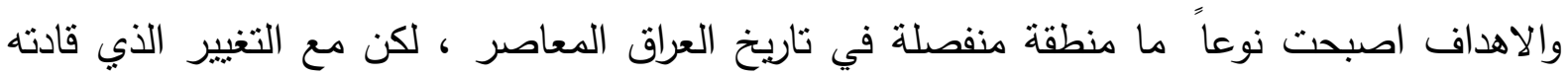

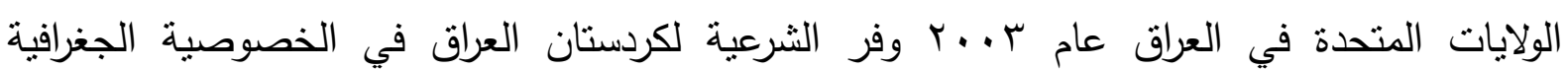
والسياسية لها ، ضمن المحاصصة بين الحزب الديمقراطي الكردستاني KDP ( محافظة دهوك واربيل )

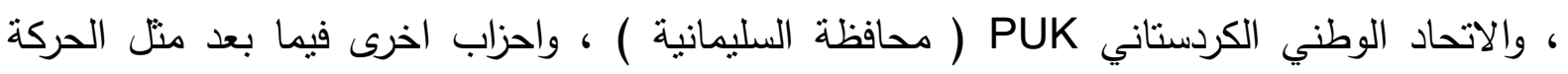

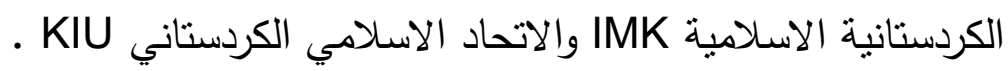

وببساطة نجح الاكراد بالفعل في ضمان منطقة حكم ذاتي في العراق يتولون السلطة فيها ، ولهم

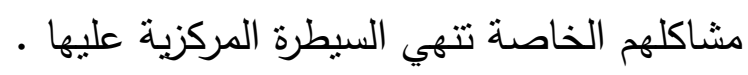
لقد طويت صفحة الفدرالية بأيدي كردية مع وجود سلطة مركزية عاجزة عن العمل في هذا الجزء من

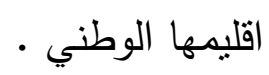

يمثل الواقع القائم الان في شمال العراق ، انفصال الأكراد عن الحكومة المركزية في بغداد وانعدام

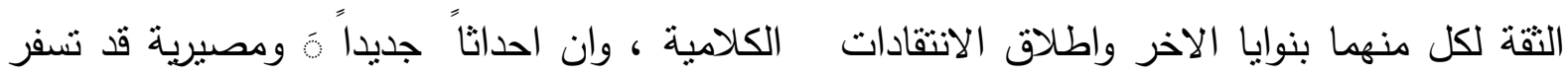
خلا العقود المقبلة ، حيث ان فكرة الانفصال او الاستقلال الكردي التي كانت مرفوضة في الاتئه الماضي

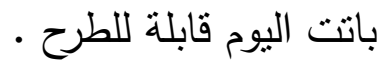

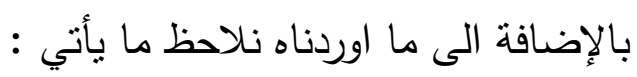
- من المؤكد ان الحس الانفصالي تغذيه مشاعر متبادلة بين الاكراد والعرب ، ولطالما نظر الاثثين

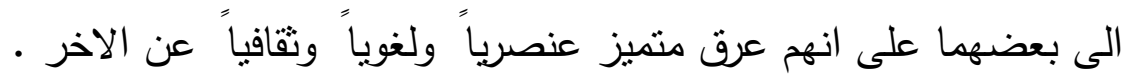


- نظراً للتاريخ الدموي والقمعي للأكراد من قبل السلطة في العراق سابقا، يسهل علينا ان نتصور

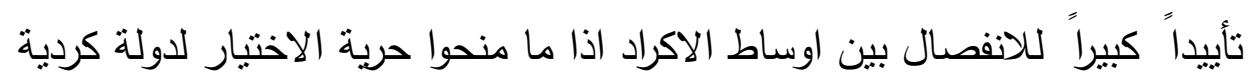

هناك دلائل عامة الان على اقامة دولة خاصة بهم في العراق، من النواحي الجغرافية والاقتصادية والسياسية والعسكرية ، غير مندمجة الى حد بعيد مع النظام المركزي في البلاد .

- ان ابرز فرصة لقيام دولة كردية سنحت للأكراد في العالم والعراق خاصى ، هي الان لنيل حرية

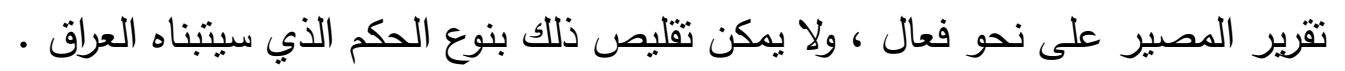

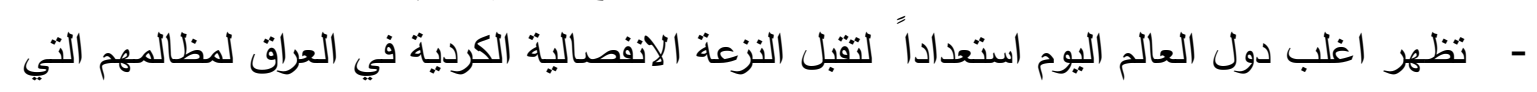

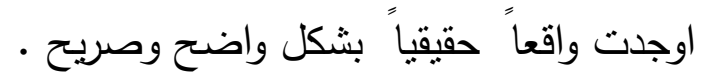

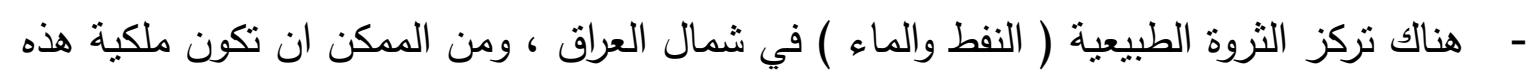

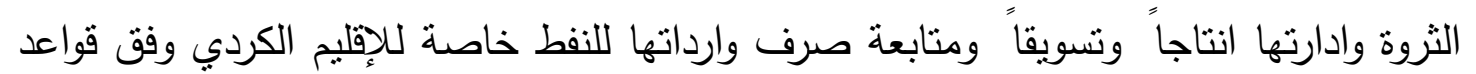

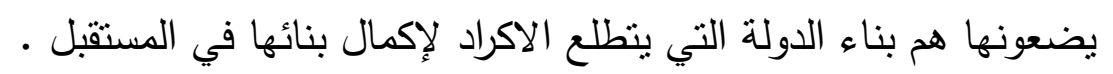

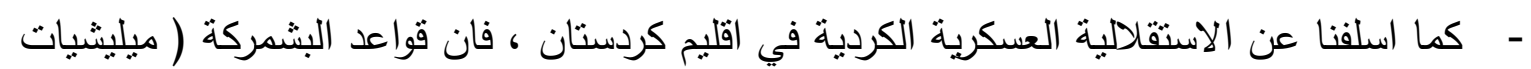

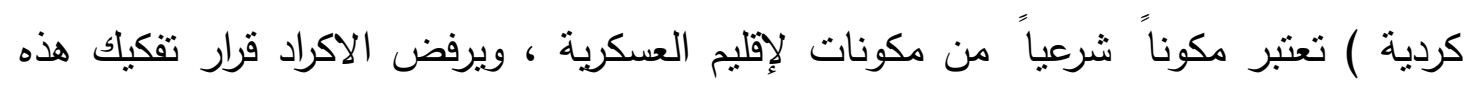

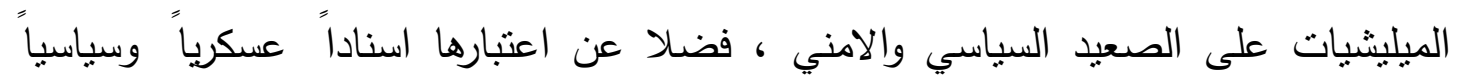
وامنية وطنية في بناء الاقليم الكردي . - طور الاكراد في العراق سياستهم ازاء تركيا باعتبارهم الجار الجديد عند حدودها الجغرافية الثرقية

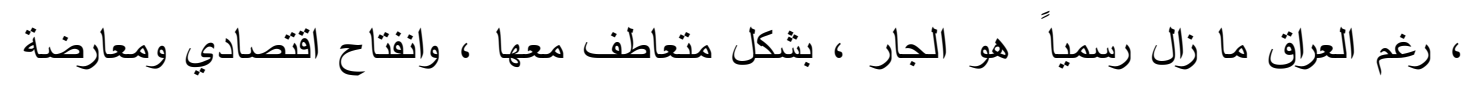

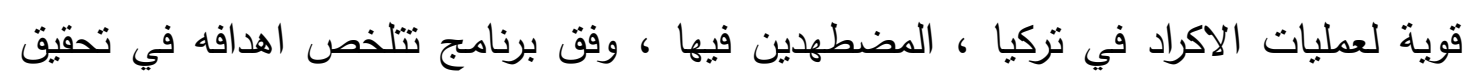
الاستقلال .

- - يميل الحكم الذاتي في اقليم كردستان العراق الى تطوير العلاقات الاميركية وضرورة التعاون

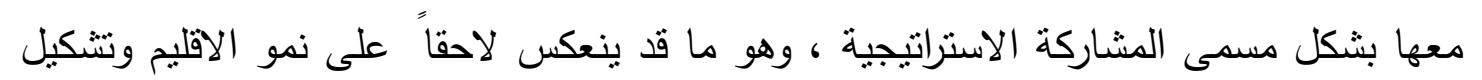

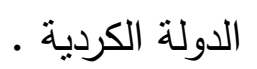


نظراً الى ما ذكر بالقدر الذي يسمح به البحث ، هناك علامات مؤكدة الى حد ما سياسية

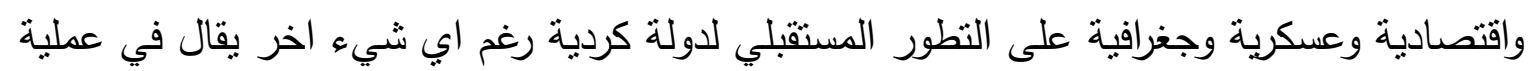
التحول هذه .

\section{مسألة كركوك}

تتقل المعلومات الاحصائية لعام 19VV عن التركيب القومي في محافظة التأميم جدول( r ) )

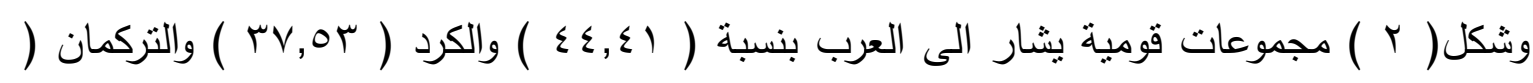

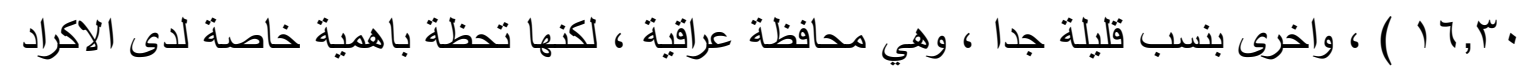
، حيث يعتبرون هذه المحافظة جزء من كردستان ( لا نخوض في تفاصيل ذلآك ) الأهميتها

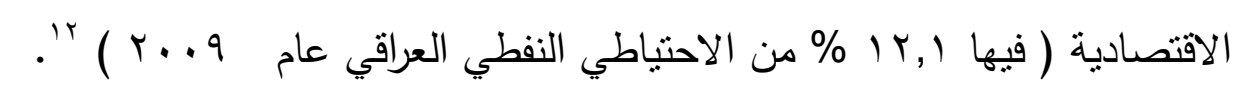

والجغرافية والثاريخية وصولا الى تسميتها ( قدس كردستان ) تعرضت هذه المدينة بالذات لعمليات

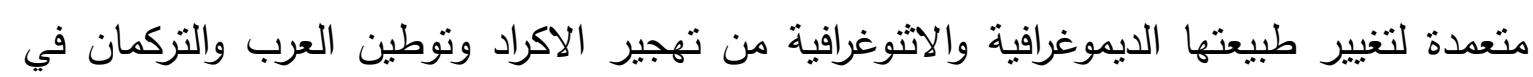

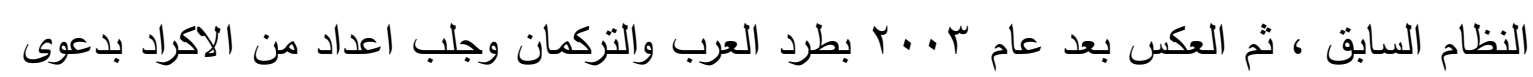

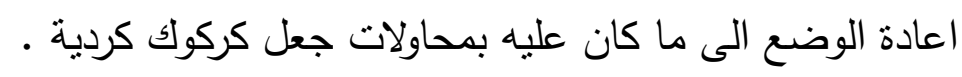

رغم المادة ( •ـ ( ) من الدستور العراقي التي تتص على تطييع الاوضاع في كركوك واجراء

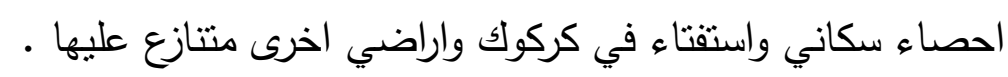

فان الوضع في كوك سيبقى مركز احتكاك بين الاكراد وحكومة المركز ، ومشاكل بين القوميات

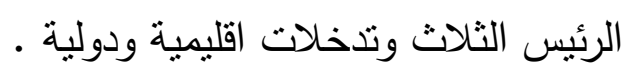

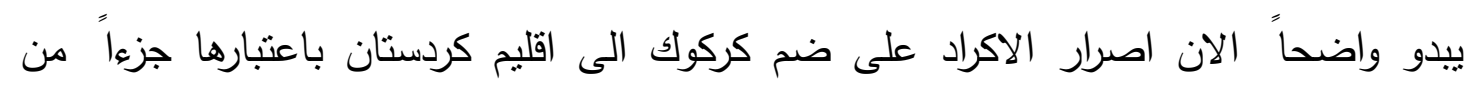

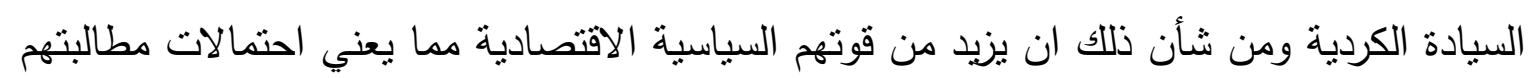
بالانفصال عن العراق وتتكيل دولة كردية مستقبلاً . 


\section{الخاتمة}

على ضوء الحقائق المقدمة في البحث ، نستطيع القول بأن الاتجاه العام للقيادة الكردية في اقليم كردستان العراق ، هو الاقليم جزء من العراق ، وضمن الوحدة الوطنية العراقية بهوية كردية ،

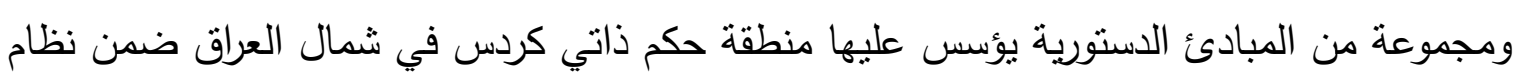

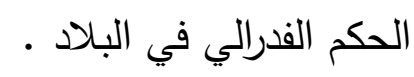

وهذا ينفي فكرة المطالبة بالاستقلال والحس الانفصالي وكردستان مستقلة . لكن دلالات نطور اقليم كردنتان بحكم ذاتي حقيقي في شمال العراق والخطوات الجريئة التي

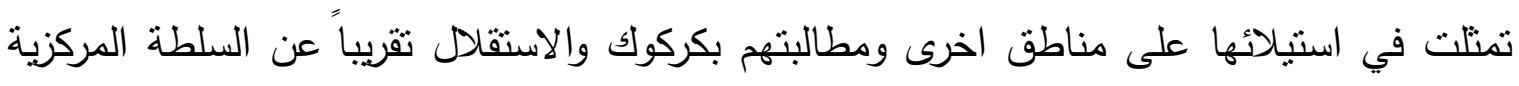

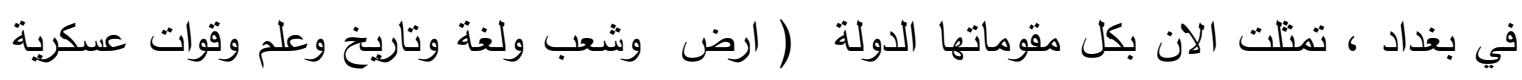

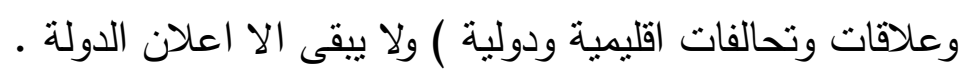

مهما يكن شكل الدولة الكردية او مميزاتها فان هذه الدراسة ترى ان كل البدائل المستقبلية توحي

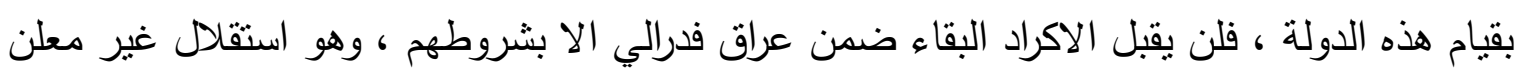

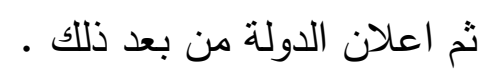

لكن الأهم من هذه الوسيلة الاقليمية والدولية الكفيلة بتحقيق ذلك ، والاكثر نفوذاً ( الولايات

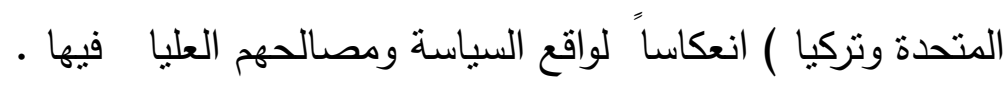
والله من وراء القصد 
( ') ملحم قربان ، المنهجية والسياسة ، بيروت ، المؤسسة الجامعية للاراسات والنشر والتوزيع ، 1911 ، ص ص • •ـ -

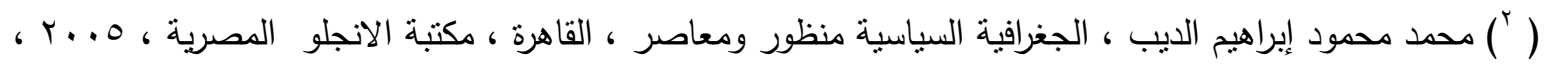

(") أمين محمود عبد الهه ، في اصول الجغرافية السياسية ، القاهرة ، مكتبة النهضة المصرية ، ع19119 ، ص ص 9r -

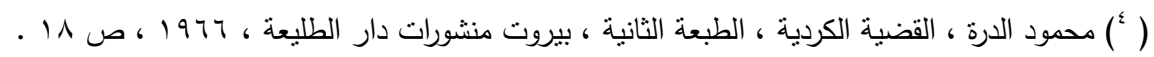

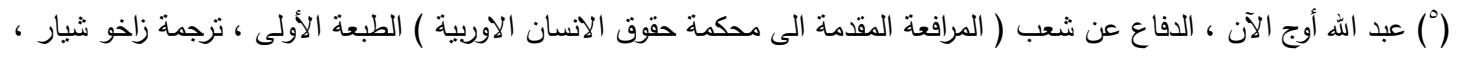

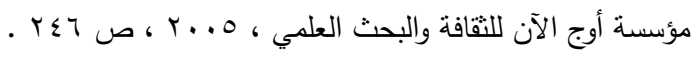

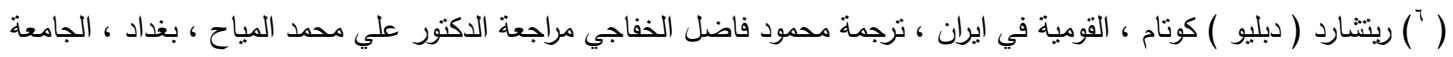

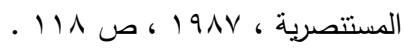

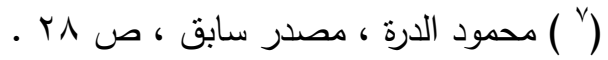

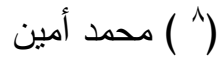

(" )جلاد الطالباني ، كردستان والحركة القومية الكردية ، بغداد ، المؤسسة العامة للصحافة والطباعة ، 1979 ، ، ص 1 ،

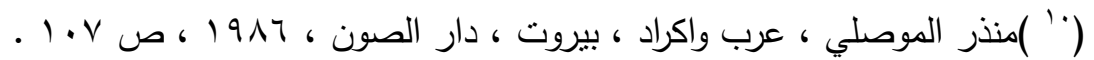

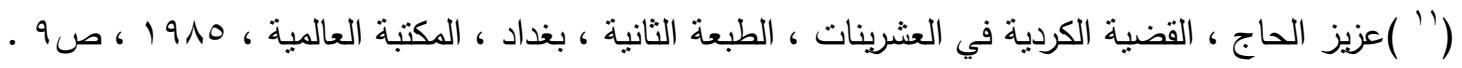

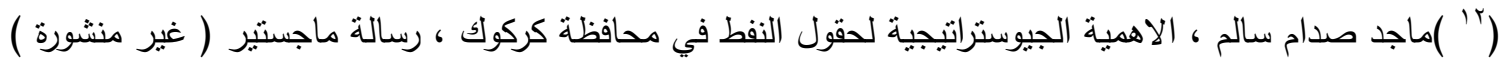

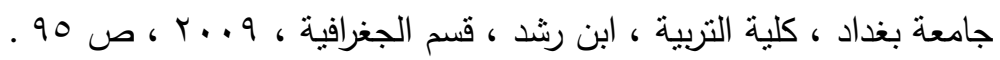


1- آوج الان،الدفاع عن شعب( المرافعة المقدمة الى محكمة حقوق الانسان الاوربية ) الطبعة الاولى ، ترجمة زاخو شيار

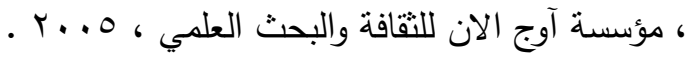

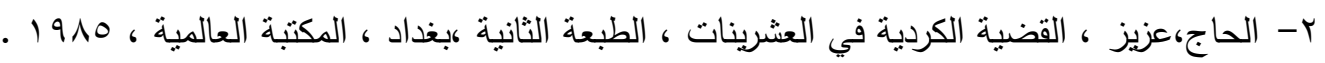

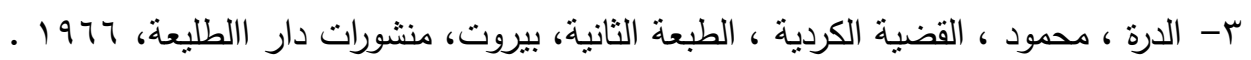

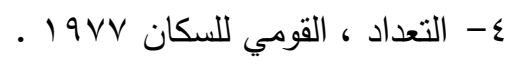

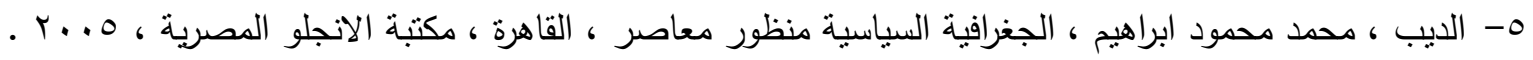

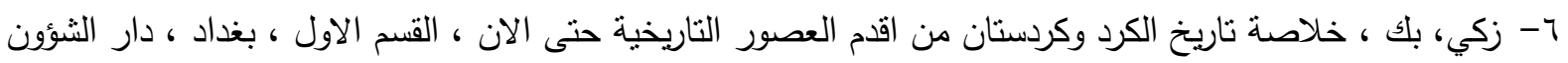

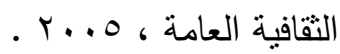

V- سالم ، ماجد صدام ، الاهمية الجيوستراتيجية لحقول النفط في محافظة كركوك ، رسالة ماجستير ( غير مشنورة ) ،

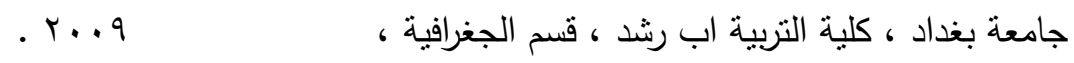

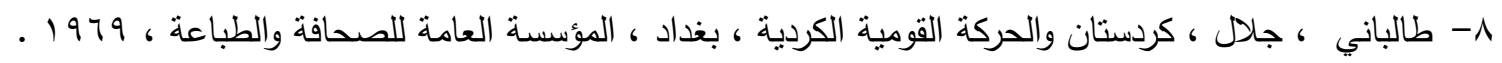

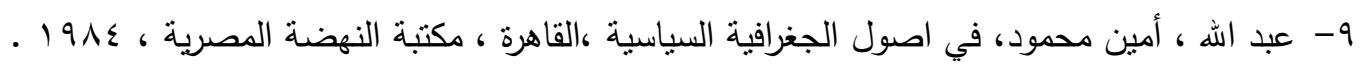
• 1. قربان ، ملحم ، المنهجية والسياسة ، بيروت ، المؤسسة الجامعية للاراسات والنشر والتوزيع ، 1919 ـ ـ

ا (. كوتام، ريتتارد ( دبليو ) كوتام ، القومية في ايرانهترجمة محمود فاضل الخفاجي ومراجعة الدكتور علي محمد ،

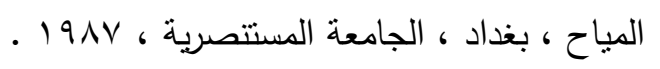
T ا. الموصلي ، منذر ، عرب واكراد ، بيروت / دار الغصون ، 1911 ـ

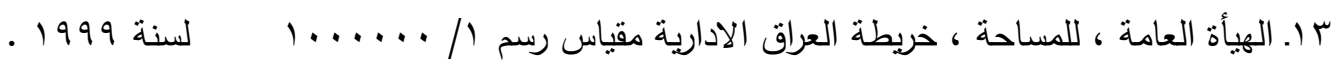

